\title{
Modernization of Public Transports in Senegal: Case of Ticket Payment Method in Dakar Dem Dikk (3Ds) Buses
}

\author{
Sall Ousmane1, Diallo Ousmane ${ }^{2}$ \\ ${ }^{1}$ School of Journalism, Information and Communication, Huazhong University of Sciences and Technology, Wuhan, China \\ ${ }^{2}$ Senegalese Radio Television (SRT), Dakar, Senegal \\ Email: usman4@yahoo.fr, ousmanesall941@yahoo.com
}

How to cite this paper: Ousmane, S. and Ousmane, D. (2018) Modernization of Public Transports in Senegal: Case of Ticket Payment Method in Dakar Dem Dikk (3Ds) Buses. Open Journal of Social Sciences, 6, 167-179.

https://doi.org/10.4236/jss.2018.67013

Received: June 6, 2018

Accepted: July 27, 2018

Published: July 30, 2018

Copyright $\odot 2018$ by authors and Scientific Research Publishing Inc. This work is licensed under the Creative Commons Attribution International License (CC BY 4.0).

http://creativecommons.org/licenses/by/4.0/

\begin{abstract}
Transport is one of the important keys of growth and socio-economic development for any country. Since 2005, Senegalese authorities have embarked on a vast fleet renewal program to modernize urban transport and professionalize the actors. The purpose of this paper is to sensitize people about the modernization of ticket payment method in Dakar Dem Dikk buses. To achieve this objective, a survey was done through the users and results have shown that the majority of participants agree to adopt the electronic ticketing smart card in public transport. This contactless payment technology is also recommended in commerce sector to facilitate and secure transactions.
\end{abstract}

\section{Keywords}

Modernization, Public Transport, Ticket Payment, Dakar Dem Dikk, Senegal

\section{Introduction}

The population of Dakar (capital city of Senegal) is estimated today according to the latest report of the National Agency for Statistics and Demography (ANSD) [1], 2016, to more than $3,500,000$ inhabitants or about $23.1 \%$ of the total population of Senegal. Due to the continually increase of the population of Dakar and the concentration of most industrial and commercial activities in the region, there is a real problem of urban mobility in the capital. The launch of the Diamniadio project called "Diamniadio Urban Pole" by the government of President Macky Sall after his accession to power is a new challenge in solving the problems of population mobility in the Senegalese capital. A large part of the population commutes daily to work, to schools, to hospitals, or to stock up on the dif- 
ferent structures and sites of the city. Every day more than 25,000 people are transported from one point to another either by Dakar Dem Dikk buses (3D) ${ }^{1}$, TATA minibus, the first public transport buses commonly called "car rapid", taxis or others.

Political and economic capital of Senegal, Dakar today appears as a city that has more public transport vehicles, the issue of urban transport is more than topical. Questioned on this situation, some users estimate that there is lack of strategies and public policies and bad organization of the sector. Each entity practices the transportation activity as he wants, there is no control nor on the state of the vehicles, their owners even less on the tariffs applied according to the route borrowed by the customers. This disorganization is causing enormous loss in economic, financial and infrastructural terms in the sector. It is clear that public transport as a motor of growth plays an important role in the economic development of a country. The modernization of the transport sector by the government becomes necessary to increase its contributory share in the gross domestic product (G.D.P). The extraordinary demographic explosion of the Dakar capital, the increase in the number of public buses by Dakar Dem-Dikk (3D) in recent years with the acquisition of more than 400 new buses and the very soon arrival of Express Regional Trains Offices (TER) require a good organization of the system to make it effective. However, with the increase number of passengers per day, the establishment of an electronic system of payment of the transport ticket is necessary to improve the management and enhance the economic performance of the 3D company which is a public company with full participation of the Senegalese state. The strong urbanization of the city has consequences for the urban mobility of Dakar residents. This is a major issue for public management of urban and interurban transport. The modernization of its financial management becomes an important lever to ensure the performance of transport companies. A global approach is needed to optimize the use of 3D buses. More and more today, it is talking about modernizing the public companies' management to make them more efficient and meet the growing needs of populations.

\section{Research Objective}

There are big issues in Senegalese public transports caused by the traditional options of ticketing payment method namely altercations between bus receivers and passengers, problem of cash to pay the transport ticket ... All of these aspects continue to make the daily movements of the population very difficult.

The main objective of the study is to modernize the payment system of ticket for Dakar Dem Dikk (3D) buses by the introduction of a "smart card" already used in several developed countries such as the Japan, France, and China [2]. This anonymous, without contact and rechargeable card will be made available to customers and will facilitate and secure the payment of tickets by clients once in the bus.

${ }^{1}$ Dakar Dem Dikk (3Ds) public bus names. 
The specific objectives of this study are to resolve conflicts that often occur between bus receivers and clients; reduce the recurring problems of small change when paying by cash; finally secure the daily revenue by allowing to no longer having cash on the bus that can be stolen during student manifestations, which often attack the 3D buses during their strikes.

This system will also provide social benefits with reduced rates for the very young and the elderly, similar to what is done in health facilities or children under 5 access cares for free and "Cesame map" granted by the state of Senegal to people of the third age. The card once produced will be sold to the customer who can recharge it in places arranged by the company $3 \mathrm{D}$, this sale will be provided by bus receivers themselves who will be trained and assigned in these places that will be determined by the leaders. The price of the ticket will be fixed according to the destination and homologate according to the line and the distance to avoid any dysfunction. The use of this electronic card will be an excellent management tool for the profitability of 3D buses in the Senegalese capital.

\section{Literature Review}

\section{Integrated Public Transport}

The modernization of transport intended to facilitate passenger's public transportation payment. Then it needs good management and organization systems. In situations they give more directed sense of integration of public transport modes in sequence a process that needs to be supported by the transport policy. To define modern public transport some aspects need to be taken into account such as, the integration of scheduling, ticketing and information, integration of design services (Potter \& Skinner, 2000). Further, the ticket is a tool for the implementation of pricing policy with consideration of operational, commercial and social objectives. Ticketing system is a translation of the tariff to a concrete means of payment for passengers and the collection of fees for operator (Mezghani, 2008) [3]. The ticket prices depending on the distance from the departure place to the destination of the passenger like in Dakar Dem Dikk.

Dakar Dem Dikk is a Senegalese urban transport company with a capital of $1,500,000,000 \mathrm{cfa}$. The company is located at 101 Sacré-Cœur 3 Pyrotechnie $\mathrm{x}$ VDN Dakar [4]. Its main mission is to offer people a transport service that meets the standards of modernity. Dakar Dem Dikk, started its service in January $1^{\text {st }}$ 2001 in a difficult socio-economic context.

Indeed, 3Ds is evolving in an unfavorable environment and must nevertheless prevail the needs of the people. To meet these challenges, the company has opted for a new managerial policy focused on user satisfaction first, job creation, promotion of social dialogue, improvement of working conditions and environment. After the urban transport component, which will see a considerably improved offer, Dakar Dem Dikk intends to develop in the medium and long term, in Africa and more particularly in Senegal, the following activities: The acquisition, rental and sale of all means of transport. We want to install air-conditioned 
buses for inter-urban transport to facilitate travel within the country.

Traveling by bus will be even more enjoyable in Senegal with the new bus ticket payment system. The government has to modernizing the public transport system to encourage people to use the bus and thereby solve the current problem of traffic jams.

Many people will welcome this new initiative. Among them, Ousseynou Badiane student at Cheikh Anta Diop University of Dakar: "I think it's a great idea, it happened to me so many times to get on the bus and realize that I did not have currency or just no cash on me. "

Despite the modernization that will bring to the public transport system, some have not stopped at the practical aspect of this new system and are wondering about the way in which it will be implemented, because Senegal has various transport companies, including private companies.

It's a system that's very prevalent in modern states like China and some European countries. The question that arises remains how it will be implemented in Senegal because there are several companies operating on different lines. We need accessibility on internet as with developed countries. It will also create another employment problem because it will require upgrading the skills of current bus receivers so they can re-enter the workforce.

This project is characterized by the introduction of smart card technology to connect all the ticketing systems of public transport. The project allows customers to buy or reload tickets smart cards from different points of sale (e.g. sales offices, distributors, and internet). The price of the trip is automatically debited from the available balance on the card account, and/or the card is recognized as a title allowing an unlimited number of trips during a given period. With each use of the card, the system captures and records the data relating to the date and time of use, the price paid, the discounts applied, the service provider organization, the trip, the institutional account.

Technology is thus increasingly interfering with the transport sector. Madrid, Chicago, Pekin or London, several cities around the world have already adopted the payment by smartcard. Dakar must seriously thinking of following them.

London remains the first example cited by professionals and experts in the field. Since 2014, the UK's capital has been offering transport users the opportunity to pay for their passage on the bus or in the metro directly with their smartcard. And since 2015, it is also possible to use his smartphone to make the transaction with Apple and Android Pay.

\section{Research Methodology}

This study using a qualitative research approach with a quantitative data and based on the previous research, literature review related to an integrated public. Transport system, observations, customer surveys, and comparative studies about an integrated ticketing system to attract car users and enhance customer satisfaction. One of the research processes is collecting primary data and sec- 
ondary data.

Research subject consist of how public transport operators implement an integrated ticketing system, and what can learn from the system. The results of this study analyze and assess the possibility developing a new integrated ticketing system in Dakar, Senegal, which intend to description and exploration of the ticket system. Further, this research will lead to conclusions, managerial implications, and interesting question for future research.

To conduct this study people were interviewed trough structured questionnaires to better have their understanding and expectations about ticketing system in public transport such as Dakar Dem Dikk in Senegal. A pilot of 100 questionnaires was sent to collect data and an appropriate statistical method was used to analyze them. Results are presented throughout tables, graphics, frequencies and percentages.

\section{Results and Factors Analysis}

The following tables show the results of the study using frequencies distribution and percentages.

\section{Frequencies Distribution}

Table 1 spotlights that out of 100 persons interviewed 10 of them use Dakar Dem Dikk (3Ds) that symbolizes $15.6 \%$ of interviewers; 35 of them use small buses that represents 54.7\%; and those who take taxi and others represent $25 \%$. From this table it deduced that the majority of people interviewed adopt private transports instead of the public one.

Table 2 shows $89.1 \%$ of people interviewed pay the transport ticket by Table 1. Transport means use for displacement through Dakar city.

\begin{tabular}{ccccc}
\hline & & Frequency & Percent (\%) & Cumulative Percent (\%) \\
\hline \multirow{4}{*}{ Valid } & Dakar Dem Dikk bus & 10 & 15.6 & 16.4 \\
& small Tata bus & 35 & 54.7 & 73.8 \\
& Taxi & 1 & 1.6 & 75.4 \\
& others & 15 & 23.4 & 100.0 \\
\multirow{3}{*}{ Missing } & Total & 61 & 95.3 & \\
& System & 3 & 4.7 & \\
& Total & 64 & 100.0 &
\end{tabular}

Table 2. Ticket payment in Dakar dem dikk bus.

\begin{tabular}{|c|c|c|c|c|}
\hline & & Frequency & Percent (\%) & Cumulative Percent (\%) \\
\hline & cash & 57 & 89.1 & 90.5 \\
\hline \multirow[t]{2}{*}{ Valid } & others & 6 & 9.4 & 100.0 \\
\hline & Total & 63 & 98.4 & \\
\hline \multirow[t]{2}{*}{ Missing } & System & 1 & 1.6 & \\
\hline & & 64 & 100.0 & \\
\hline
\end{tabular}


cash and $9.4 \%$ have other ways to pay. The majority of respondents pay their tickets by cash.

Table 3 indicates that $67.2 \%$ of respondents estimate this payment method is imposed by the company where by $32.8 \%$ of participants think that is not the case.

Table 4 manifests that $10.9 \%$ of respondents never have problem of cash while paying the transport ticket in the bus; $53.1 \%$ of them confirm that they often have problem of cash paying while getting in the bus and $35.9 \%$ don't often have this kind of problem in the bus. It can conclude most of the people interviewed often have cash paying in public transports.

Table 5 indicates that $10.9 \%$ totally agree the bus ticket should be replaced by an electronic card; $23.4 \%$ agree too but $43.8 \%$ not agree at all they wish to maintain the bus ticket and $21.9 \%$ are neutral about the situation. Roughly speaking, $34.4 \%$ agree electronic card should be adopted to pay the transport ticket in public transport and $43.8 \%$ don't share the same point.

Table 6 gives ideas about bus receivers and passengers that's to say $60.9 \%$ of participants confirm never have any altercations with bus receivers while $10.9 \%$ of them often get troubles and $28.1 \%$ of respondents not often have altercations with bus receivers. This table shows the atmosphere between bus receivers

Table 3. Ticketing payment method.

\begin{tabular}{ccccc}
\hline & & Frequency & Percent (\%) & Cumulative Percent (\%) \\
\hline \multirow{3}{*}{ Valid } & yes & 43 & 67.2 & 67.2 \\
& no & 21 & 32.8 & 100.0 \\
& Total & 64 & 100.0 & \\
\hline
\end{tabular}

Table 4. Problem of cash paying while getting the car.

\begin{tabular}{ccccc}
\hline & Frequency & Percent (\%) & Cumulative Percent (\%) \\
\hline \multirow{3}{*}{ Valid } & never & 7 & 10.9 & 10.9 \\
& often & 34 & 53.1 & 64.1 \\
& not often & 23 & 35.9 & 100.0 \\
& Total & 64 & 100.0 & \\
\hline
\end{tabular}

Table 5. Ticket as electronic card.

\begin{tabular}{ccccc}
\hline & Frequency & Percent (\%) & Cumulative Percent (\%) \\
\hline \multirow{4}{*}{ Valid } & totally agree & 7 & 10.9 & 10.9 \\
& agree & 15 & 23.4 & 34.4 \\
& not agree & 28 & 43.8 & 78.1 \\
& neutral & 14 & 21.9 & 100.0 \\
& Total & $\mathbf{6 4}$ & $\mathbf{1 0 0 . 0}$ & \\
\hline
\end{tabular}


and passengers is not quite good even if the majority of people interviewed never get troubles.

Table 7 confirms $43.8 \%$ of respondents are very satisfied with the treatment they receive from the receivers in public transports; $7.8 \%$ of them also feel good about their treatment but $39.1 \%$ of them are not satisfied at all and $9.4 \%$ of respondents even express how the treatment is very bad in public transports. The majority of people interviewed appreciate the treatment they receive once in public transport.

As Table 8 about tickets price $90.6 \%$ of respondents think it's acceptable but $8.4 \%$ say the bus ticket price is not acceptable.

Table 9 shows $39.1 \%$ of people interviewed spend more than $45 \mathrm{mn}$ to arrive at their respective destinations $23.4 \%$ of them spend more than 1 hour and $36 \%$ at least spend $30 \mathrm{mn}$.

\section{Factors Analysis}

Table 10 shows the existence of relationship between variables; some are positively correlated that means the variable has a positive influence on the other variable for instance how do you pay your ticket? And, the transport used for displacements $+33.1 \%$. And other variables are negatively correlated that indicates

Table 6. Altercation with bus receiver.

\begin{tabular}{ccccc}
\hline & & Frequency & Percent (\%) & Cumulative Percent (\%) \\
\hline \multirow{3}{*}{ Valid } & never & 39 & 60.9 & 60.9 \\
& often & 7 & 10.9 & 71.9 \\
& not often & 18 & 28.1 & 100.0 \\
& Total & 64 & 100.0 & \\
\hline
\end{tabular}

Table 7. Passenger treatment in buses.

\begin{tabular}{ccccc}
\hline & & Frequency & Percent (\%) & Cumulative Percent (\%) \\
\hline \multirow{4}{*}{ Valid } & very good & 28 & 43.8 & 43.8 \\
& good & 5 & 7.8 & 51.6 \\
& bad & 25 & 39.1 & 90.6 \\
& very bad & 6 & 9.4 & 100.0 \\
& Total & 64 & 100.0 & \\
\hline
\end{tabular}

Table 8. Bus ticket price.

\begin{tabular}{ccccc}
\hline & Frequency & Percent (\%) & Cumulative Percent (\%) \\
\hline \multirow{4}{*}{ Valid } & 2 & 3.1 & 3.1 \\
& very acceptable & 56 & 87.5 & 90.6 \\
acceptable & not acceptable & 5 & 7.8 & 98.4 \\
& 4 & 1 & 1.6 & 100.0 \\
& Total & 64 & 100.0 & \\
\hline
\end{tabular}


Table 9. Time the bus takes to arrive at destination.

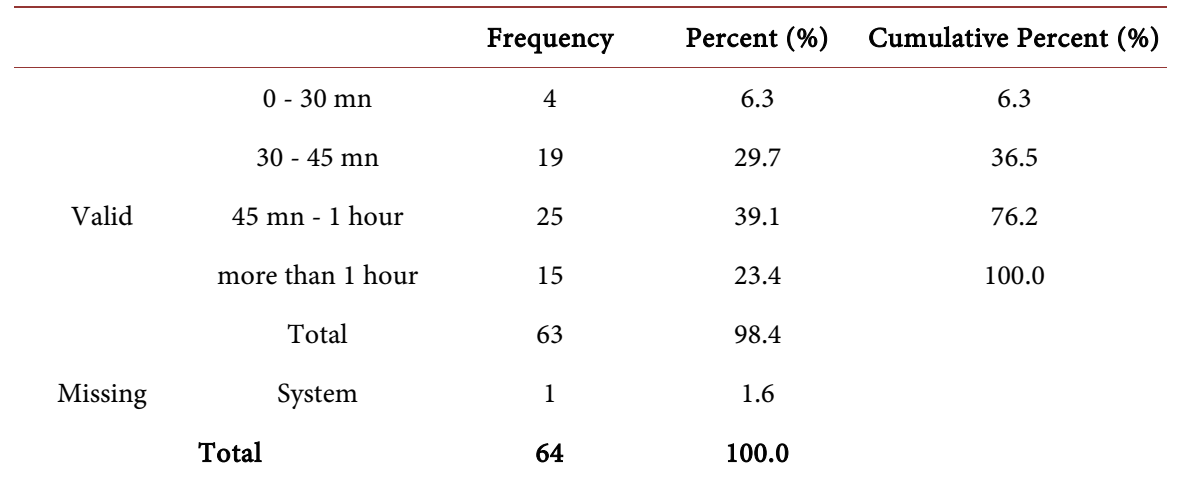

Table 10. Correlation matrix.

\begin{tabular}{|c|c|c|c|c|c|c|c|c|c|}
\hline & actor & & 1 & 2 & 3 & 4 & 5 & 6 & 7 \\
\hline \multirow[t]{7}{*}{ Correlation } & 1 & What is your age? & 1 & & & & & & \\
\hline & 2 & $\begin{array}{l}\text { Which transport do you use for your displacement in } \\
\text { Dakar city? }\end{array}$ & -0.2 & 1 & & & & & \\
\hline & 3 & $\begin{array}{l}\text { Do you think the bus ticket should be an electronic } \\
\text { card? }\end{array}$ & -0.238 & 0.134 & 1 & & & & \\
\hline & 4 & How many times do you take the bus a day? & 0.064 & 0.031 & 0.124 & 1 & & & \\
\hline & 5 & Do you once get altercation with the bus receiver? & 0.173 & 0.163 & -0.037 & 0.233 & 1 & & \\
\hline & 6 & How do you pay your ticket in Dakar dem dikk bus? & -0.111 & 0.331 & -0.039 & -0.227 & -0.066 & 1 & \\
\hline & 7 & What do you think about the bus ticket? & -0.154 & -0.105 & -0.119 & 0.147 & 0.158 & 0.069 & 1 \\
\hline
\end{tabular}

Table 11. Results of Chi-Square Tests $(\mathrm{N}=100)$.

\begin{tabular}{cccc}
\hline & Value & df & Asymp. Sig. (2-sided) \\
\hline Pearson Chi-Square & $18.683^{\mathrm{a}}$ & 6 & 0.005 \\
Likelihood Ratio & 16.538 & 6 & 0.011 \\
Linear-by-Linear Association & 3.558 & 1 & 0.059 \\
N of Valid Cases & 63 & & \\
\hline
\end{tabular}

a. 8 cells $(66.7 \%)$ have expected count less than 5 . The minimum expected count is .11. ${ }^{* *}$. Correlation is significant at the 0.01 level (2-tailed). $\mathrm{Df}=$ Degree of freedom.

the influence of a variable is less important on the other for example between the age and the ticket should be electronic $-23.8 \%$, it is concluded that the age has no influence on the nature of the ticket.

\section{Chi-Square}

As shown in Table 11, $\mathrm{P}=0.005, \mathrm{df}=6$ means the regression analysis confirmed that the ticket payment by electronic card is not related to the age of users. The relationship between the electronic card and the age is not significant.

\section{Discussion}

Dakar Dem Dikk (3D) bus should be the preferred means of transport in most 
cases in Dakar. The bus is the cheapest way to get around Dakar. The network is well developed and can go virtually anywhere. Buses are of variable quality, some are air-conditioned, modern and others are more outdated.

The difficulty lies not so much in orientation but rather in finding the right means of locomotion to not spend time in transportation. As in all major capital cities, the population of Dakar is growing day by day, so public transport is very popular for travel. Moving to Dakar city with 3Ds is economical and simple.

If you want to check the number of passengers that a bus 3Ds can board, you may not find a very precise answer, at least not easily. Indeed, standard buses have a capacity of 40 people. In reality, things are very different and at peak times, the bus can accommodate 3 times (or more) than the displayed capacity. From then on it raises the question of how the ticket is paid in these conditions especially at peak times. for example is it possible to quickly pay the ticket and give way to his next, the study done here shows the existence of major difficulties in obtaining the ticket and travel quietly. It often happens that problems of small currencies arise and that customers and receivers dispute in the bus the table no 4 indicates that indeed $53.1 \%$ of the customers questioned said to have had at least once this kind of situations. This often leads some travelers to forget their currency. For Dakar users, the most important thing is to reach the destination. For a long time, the notion of comfort in public bus transportation has not been on the agenda. For a tourist who travels at random to Dakar, the most surprising once inside a bus filled to the ground is that the atmosphere guesses that the journey will be hellish. Table 9 shows that $39 \%$ of the respondents indicate that the bus takes at least 45 minutes to 1 hour before they get out of the bus. This explains how the conditions of the public bus transportation are difficult. The atmosphere: a lack of suffocating space, difficult even sometimes to put feet on the ground, brouhahas, groans of pain, complaints and laments, standing most often, rarely sitting.

Modernize the payment system will be an innovation in the modernization of interurban passenger public transport in the capital city of Dakar. It is a matter of simplifying the act of buying tickets by saving time and securing revenue.

Table 2 shows $89.1 \%$ of people interviewed pay the transport ticket by cash that represent the majority while $9.4 \%$ of the participants use the traditional card of payment. With the rapid development of internet and social networks changes of behavior become necessary. Public managers have to innovate to improve the quality of transportation services in Dakar.

Pay for public transit directly with your credit card instead of getting a ticket in advance or having some changes in your pockets? This is the challenge that has been launched in cities around the world in recent year. Dakar the capital city cannot be in rest as indicated in Table $748.5 \%$ of participants are not satisfied of their treatment while getting into 3Ds public buses therefore, improvements are needed to enhance the relationship between clients and receivers. 
Public transport in Dakar is a real headache for users and clients. Everyone complains of the easy shift of language and behavior on the part of receivers and drivers. As shown in Table 6 10.9\% of respondents indicate that they often have altercations with receivers. In these frequent contacts between the carriers and the users of the bus, the receiver plays a central role: it is him who guides the driver, mobilizes the customers, winds the tickets and collects and classifies the money, answers to various requests from customers, etc. In order to bring about a change of mentality in this critical sector for every patient, worker, shopkeeper or simple housewife who has to travel every day on a bus, it is obvious that we have to start with a sensitive aspect with visible impact., particularly by targeting the carrier/client contact link that is the receiver. Table 6 gives ideas about bus receivers and passengers $60.9 \%$ of participants confirm never have any altercations with bus receivers while $10.9 \%$ of them often get troubles and $28.1 \%$ of respondents not often have altercations with bus receivers. It concluded that, the atmosphere between bus receivers and passengers is not quite good even if the majority of participants interviewed never get troubles.

In the face to face interview with clients, one of them explained his history once he gets in the bus:

"I suffered an injustice yesterday in the bus Dakar Dem Dikk registration number 9108 I had $1000 \mathrm{~F}$ cfa with me I took the bus at Liberte 5 So after the departure I go to the ticket office to pay my ticket $250 \mathrm{fcfa}^{2}$ for Zac Mbao but the receiver did not accept my 1000 f because it's his first trip and he has no change and I understood I told him to write the rest of the currency on the back of the ticket when we arrive at Zac Mbao he will be able to give me back what he refused. I tried to gather a few travelers to pay with my 1000 fcfa but without success thereafter I went to sit at my place without paying the ticket and one of the two agents ordered me to get off the bus at the next stop what I totally refused because I have my money and I tried to pay".

The results in Table 4 confirm this issue which happens frequently in the 3Ds public buses. It concluded the necessity of modernization of the ticket payment by passengers once they get into the bus. This will improve the relationship between 3Ds workers and users. During discussions with participants about the replacement of the traditional ticket payment by an electronic ticket, the majority $43.8 \%$ are reticent of the new change which will bring the method of paying the ticket while $34.4 \%$ wish the innovation with the introduction of the electronic ticket these results were shown in Table 5.

It is obvious that any change cannot be accepted immediately by all, it takes time and therefore managers of the 3Ds public buses have to carry out a good campaign of communication to inform customers about the many advantages of the electronic ticket [5]. By explaining that this will save time once getting into the bus, also there will not be a risk to forget their currency with the receivers or to have regular disputes with them. A sample of bus user paying with his smart card in Rwanda as shown in Figure 1.

${ }^{2}$ Fcfa local currency used in the West African countries colonized by France. 


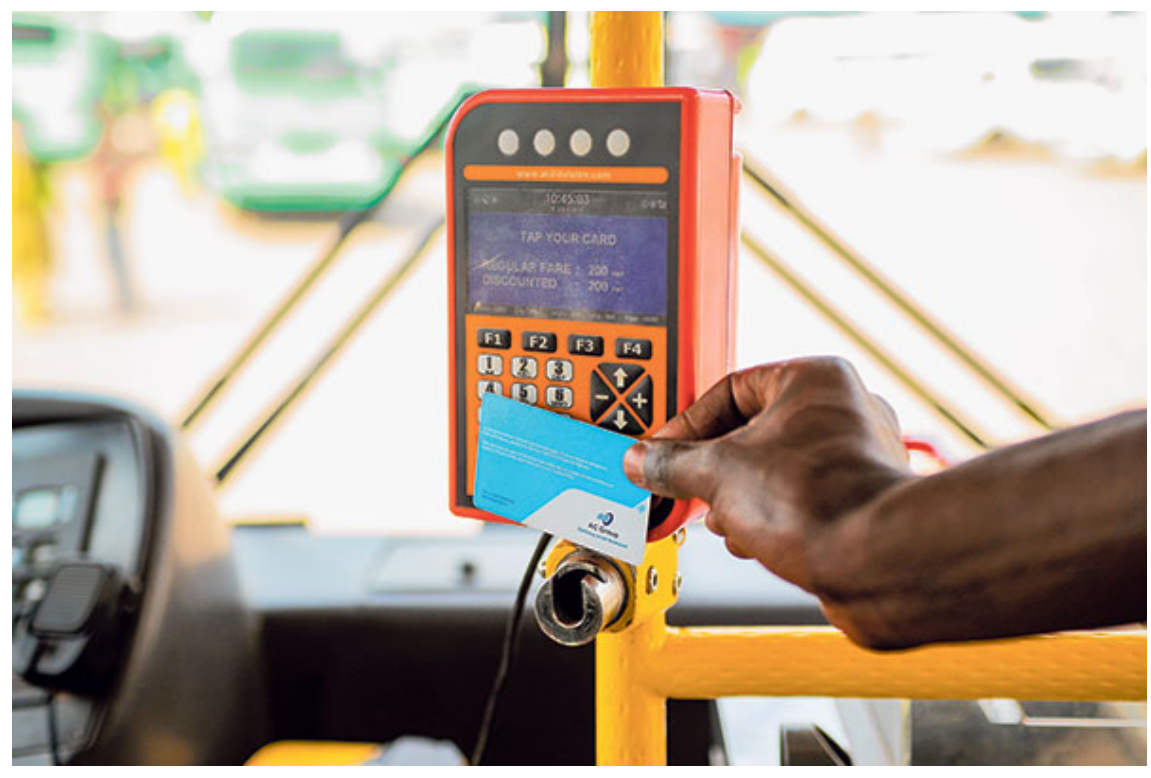

Figure 1. A sample of bus user paying with his smart card in Rwanda.

The 3Ds public bus is not performing well as indicated in Table 1 only $15.6 \%$ of participants use the public buses for their daily transportation in Dakar the capital city. Therefore, a new reform should be carrying out by leaders to modernize this important public sector in order to enhance the quality of service delivery.

\section{Conclusions}

The purpose of this work was to assess and analyze the link between urban form, mobility behavior and the dysfunction of the public transport supply in an agglomeration African city with strong urban growth like Dakar. Specifically, it was in a first time, to evaluate and analyze the influence of urban characteristics on the different choices of mobility, and secondly to assess and analyze the impact of modernization of public transports in Dakar through Dakar Dem Dikk buses.

Transport management is a major issue in the global competition. In many parts of the world, cities are expanding. Well-planned urban planning has considerable implications for business growth and, in this area; the quality of transport often plays a key role. But problems do not arise everywhere in the same way. Senegal is a textbook case.

The demand for urban transport services has grown steadily in Dakar. Global population growth and rapid urbanization have led to the rapid development of the Senegalese capital city [6], which is rapidly impacted by a sudden increase in demand for transport, infrastructure and services whose provision has fallen far behind. Property and rent prices often explode in Dakar, forcing companies and their employees to move to the outskirts, a phenomenon that increases daily commuting. Some developed countries have been able to keep this demand under control. This sometimes involves policies that may appear unfriendly to 
owners or users of private vehicles. The conventional transport system is a good indicator of the development of some African cities, because it is strongly correlated with the level of socio-economic development of the countries and the heterogeneity of living standards is no longer necessarily adapted and sufficient.

The transport and mobility circuit therefore need to be updated and studied in depth to understand its complexity, but this requires, as a first step, an analysis of the existing transport system [7]. The Senegalese transport system is no exception. Its analysis requires taking into account as everywhere else three elements: services, equipment infrastructures and users. Firstly, services are the means of transport: vehicles deployed by the public authorities or by private entrepreneurs for the mobility of users, the private car, the bus, etc. On the African continent in general, transport services can be divided according to the level of socio-economic development of the countries: the more a country is developed, the more it has technico-financial resources to properly equip itself with efficient transport services [8]. Nowadays, with the development of new technologies, information and communication, countries must integrate them to improve public service delivery. Senegal, must take advantage of the development of the internet and new communication technologies to project itself in the future [9] especially with the next arrival of the regional express train (RET) already planned by 2019 .

\section{Recommendations}

The results of the study recommend that the Senegalese public transport authorities to use the multiple benefits of new technologies of information and communication on the service delivery. Rapid urbanization in Dakar puts tremendous pressure on traditional means of transportation. The site is huge and information technology can help. They may seem expensive but are necessary to modernize transport sectors and to cope with this urbanization which, according to the official projections, will not slow down in the next years [10].

For a good implementation of this new system, the study recommends to the authorities of Dakar Dem Dikk (3Ds), to proceed with a training of the receivers for the sale of the cards and their reloading once these cards produced by a system secured, digitalized and coded. The establishment of special offices dedicated to these services where receivers and other agents of control will be assigned to meet the needs of the clients effectively.

Dakar Dem Dikk authorities have to study the feasibility of deploying a contactless payment system in the buses for example by using electronic card [11]. The card would automatically communicate with a short-range reader and charge the amount due. This type of contactless payment has been experimented for several years, but is not yet commercially deployed in Senegal. Modernize the payment system will be an innovation in the modernization of interurban passenger public transport in the capital city of Dakar. It is a matter of simplifying the act of buying tickets by saving time and securing revenue.

From our interviews it's noticed that $89.1 \%$ of users pay the transport ticket by 
cash that represent the majority while $9.4 \%$ of the participants use the traditional card of payment. Modernizing a transport company does not only mean renewing its fleet, it also means putting in place the modern means of management, control and reliable communication to build customer loyalty. The study recommends the use of electronic card for the ticket payment to enhance the relationship between receivers and customers.

In Senegal, it may not be time yet for taxi-fliers like in Dubai, but small actions could help lift the friction on public transports [12]. Solving currency problems may seem easy as there are solutions offered by technology. The study recommends the use of the new ticket payment system to enhance the public transportation and increase the performance of the organizations as well as conditions of people movement.

With this fast system, secure and reliable, the research will recommend its generalization for all means of payment in shops, stores, and all types of urban transport. For that, it will be necessary to evaluate this first experiment implemented in the Dakar Dem Dikk (3Ds) buses in order to correct all the dysfunctions noted in its application.

\section{References}

[1] Projection démographique, rapport annuel population du senegal/MEFP/ ANSD-mars2018.

[2] Mezghani, M. (2008) Study on Electronic Ticketing in Public Transport. European Metropolitan Transport Authorities.

[3] Dakar Dem Dik annonce Sénégal Dem Dik avec des bus climatisés, 29 juillet 2016, La vie Senegalaise.

[4] Kabona, E. (2017) E-Ticketing Pays off for Rwanda's Public Transport Operators. THE East African.

[5] European Parliamentary Research Service (2014) Integrated Urban E-Ticketing for Public Transport and Touristic Sites.

[6] Barrow, K. (2016) Work Begins on Dakar TER Project. International Railway Journal,

[7] Ivan, C. and Balag, R. (2015) An Initial Approach for a NFC M-Ticketing Urban Transport System. Journal of Computer and Communications,

[8] Jaures, N. (2018) Le rôle des transports publics en Afrique au centre d'un séminaire, AfrikMak.

[9] Public Transport ITS Committee, White Paper on the Application of NFC Technology in Public Transport, Asoc. (2013) Foro de Nuevas Tecnologíasen el Transporte, ITS Espana. 1st Edition, C/ Serrano, 216-1odcha. 28016 Madrid.

[10] Bouessel, Charles du Bourg, Sénégal: Les mille et une promesses du bus rapide de Dakar, 30 mai 2017, Jeune Afrique.

[11] Tuikka, T. and Isomursu, M. (2009) Touch the Future with a Smart Touch. VTT Tiedotteita-Research Notes 2492, 280 p.

[12] Mut-Puigserver, M. and Payeras-Capella, M. (2012) A Survey of Electronic Ticketing Applied to Transport. Computers \& Security, 31, 925-939.

https://doi.org/10.1016/j.cose.2012.07.004 